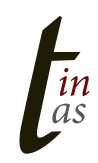

Tintas. Quaderni di letterature iberiche e iberoamericane, 10 (2021), pp. 19-31. ISSN: 2240-5437.

http://riviste.unimi.it/index.php/tintas

\title{
Revisión del mito de la sororidad en reescrituras hispanoamericanas del siglo XX: Las hermanas Agüero (1997) de Cristina García
}

\author{
E. Helena Houvenaghel \\ Universiteit Utrecht \\ e.m.h.houvenaghel@uu.nl
}

\section{Hermanas antiguas ENTRE AliANZA Y RIVAlidad}

En las tradiciones bíblica ${ }^{1}$, grecorromana y egipcia, los pares de hermanos varones más conocidos son enemigos. Los casos de José y sus hermanos, de Jacob y Esaú, de Caín y Abel, de Eteocles y Polinices, de Rómulo y Remo, y de Set y Osiris lo ejemplifican. La rivalidad es causada por el deseo del mismo objeto, como por ejemplo la herencia del trono o el poder sobre una tierra ${ }^{2}$. Frente a esta mayoría de pares de hermanos opuestos, existen también hermanos míticos estrechamente unidos. En la mitología griega, por ejemplo, Castor y Pólux comparten un vínculo tan fuerte que cuando Castor muere, Pólux renuncia a la mitad de su inmortalidad para estar con su hermano.

¿Qué pasa con las hermanas? En los mitos sobre la relación entre una hermana y un hermano, predomina la relación de cooperación. En la cultura griega destaca la alianza entre Artemisa y su hermano gemelo Apolo. Desde el momento mismo de su nacimiento, Artemisa siempre le ayuda y defiende. Juntos, los hermanos gemelos colaboran en muchos proyectos y forman una alianza poderosa. En la épica griega, es Electra quien le salva a su hermano Orestes al sacarlo del país cuando Clitemnestra quiere matarlo. En la tradición bíblica, Miriam también se presenta como protectora de su hermano menor

\footnotetext{
${ }^{1}$ Incluimos, en este artículo, referencias a relatos del Antiguo Testamento sobre la hermandad y la sororidad. Sin embargo, se plantea la pregunta de saber si se puede hablar de mitos en el caso de la tradición bíblica, ya que es monoteísta mientras que en la mitología suelen interactuar diferentes dioses. Graves y Patai toman distancia de la discusión monoteísmo/politeísmo y enfocan el origen histórico del texto bíblico. Recalcan, en este contexto, que la Biblia tiene sus raíces en textos épicos llenos de referencias míticas cuyas huellas se han borrado posteriormente. Graves, Robert y Patai, Raphael, Los mitos hebreos, Madrid, Alianza, 2000, p. 4.

${ }^{2}$ Para un análisis del fenómeno de la violencia fundada en el deseo, véase Girard, René, La violencia y lo sagrado, Barcelona, Anagrama, 2005. Llano Cifuentes traslada el mismo fenómeno a la sociedad contemporánea: Llano Cifuentes, Alejandro, Deseo, violencia, sacrificio. El secreto del mito según René Girard, Pamplona, Eunsa, 2004.
} 
Moisés cuando lo deposita en la canastilla en el Nilo y consigue así salvarle la vida. En el otro extremo se halla el mito de Medea, quien mata a su hermano pequeño Apsirto para que se pueda escapar de su tierra natal con Jasón, llevando el vellocino de oro.

En los mitos sobre la relación entre dos hermanas, se presenta un contraste entre rivalidad/alianza. Empezando por el extremo de la rivalidad, la Biblia dedica un capítulo a la competitividad entre las hermanas Lía y Raquel, ambas casadas con Jacob. El objeto de deseo por el que Lía y Raquel compiten es la maternidad o la producción de descendencia. La hermana vencedora en virtud de su fecundidad es Lía, a pesar de que Jacob prefiere la hermosa Raquel. La mitología griega nos presenta un mito que expresa el contraste entre dos percepciones de la moralidad a través de la sororidad. La valiente Antígona y su hermana cobarde Ismene se oponen en que Ismene, incapaz de saltarse las normas impuestas por la ley, no ayuda a Antígona en el acto moral de enterrar y honrar a su hermano.

En el otro extremo del eje rivalidad/alianza se encuentran los mitos que ponen de relieve la fuerza que existe en el compartir proyectos entre hermanas. La mitología griega ofrece varios casos de agrupaciones de hermanas que colaboran para conseguir un objetivo común. Las Moiras, por ejemplo, son tres temibles y poderosas hermanas quienes juntas hacen cumplir el destino de los hombres; las nueve Musas son las hermanas quienes inspiran las diferentes artes y que son invocadas por los artistas para recibir la inspiración divina. Dichas hermanas son tan unidas que, aunque cada una de ellas tiene su propio nombre y se dedica a una tarea específica, se suelen citar a menudo como conjunto.

El contraste entre oposición y complicidad se tematiza en los mitos cuyo protagonismo recae en tríadas de hermanos. En la cultura egipcia, por ejemplo, se construye simultáneamente una relación de rivalidad entre Osiris y su hermano mayor Set, quien le asesina, y una relación de complicidad entre Osiris y su hermana gemela Isis, quien le insufla nueva vida. En la tradición griega, Helios (el Sol), se opone a su hermana Selene (la Luna), mientras que la tercera hermana, Eos (el Alba), media entre ellos y sirve como figura de transición. Los mitos antiguos expresan, así, de diferentes maneras la tensión entre rivalidad y alianza que caracteriza la sororidad.

\section{RESIGNIFICACIÓN DE LA HERMANA EN LA LITERATURA HISPANOAMERICANA DEL SIGLO XX}

La dinámica rivalidad/alianza marca también el tono de las reescrituras de los mitos de sororidad producidas en la Hispanoamérica del siglo XX. Tanto la rivalidad como la alianza sirven, en los textos del siglo XX, para dar expresión a cuestiones sociales relacionadas con la desigualdad y la falta de un sentido de comunidad.

El mito antiguo de la rivalidad de Caín y Abel, por ejemplo, le inspira a la escritora judeomexicana Angelina Muñiz Huberman una reescritura en clave femenina a través del cuento «La ofrenda más grata» $(1967)^{3}$. La reescritura convierte al hermano mayor Caín en una hermana, quien siente envidia hacia el hermano varón menor, el hijo predilecto de la familia a pesar de que no merece el lugar privilegiado que se le da. Por rebeldía frente

3 «La ofrenda más grata» de la autora judeomexicana Angelina Muñiz Huberman se publicó en 1967 en la revista Cuadernos del Viento y se recogió posteriormente en el volumen de cuentos Huerto cerrado, huerto sellado (1985). El texto, de índole híbrida, oscila entre cuento, ensayo, poesía. Muñiz Huberman, Angelina, Huerto cerrado, huerto sellado, México, Oasis, 1985. 
a esta injusticia ${ }^{4}$, la hermana mayor mantiene una relación incestuosa con su hermano menor y después lo mata. Al convertir la figura del hermano primogénito en hermana primogénita, Angelina Muñiz Huberman invita a poner en entredicho la predilección tradicional por el hijo varón, en detrimento de los derechos y talentos de la hija mayor. Sustituyendo el concepto de la familia por el de la sociedad, el cuento puede interpretarse como una denuncia de la desigualdad de género. La historia sobre la figura de Caín en femenino enfatiza, así, «el dolor de la hermana que lucha contra la sociedad y la tradición para conseguir un espacio que le es negado» y centra la atención en «la lucha de quien está en desventaja debido a criterios injustamente impuestos» ${ }^{5}$.

La falta de solidaridad y cooperación entre las hermanas clásicas Antígona e Ismene, a su vez, es transformada en una alianza en la pieza Antígona (2000) del escritor peruano Watanabe ${ }^{6}$. La creación de Watanabe encaja en el contexto de la reconstrucción del Perú tras el conflicto político que en las décadas de los ochenta y noventa dio lugar a conflictos armados y que dividió el país. En la reescritura de Watanabe, la hermana Ismene, al final de la pieza, realiza el entierro de su hermano Polinices, y así reconoce que su hermana Antígona tomó la decisión correcta al oponerse a la ley. «Se produce, entonces, la transmisión de una fuerza transformadora de hermana a hermana ${ }^{7}$ : la actitud valiente de Antígona causa, después de su muerte, un cambio en Ismene y le sirve a Ismene de fuente de inspiración para repensar su actitud y elegir otro camino. Así, el miedo y la cobardía iniciales de Ismene se transforman en valentía y la falta de cooperación se convierte en la voluntad de un compromiso. La transformación de Ismene al final de la pieza representa, en el contexto peruano, la posibilidad de la reconstrucción de una comunidad coherente después del conflicto armado $^{8}$. A continuación, profundizaremos más en detalle en un estudio de caso cubano que sirve como ejemplo de las posibilidades de resignificación que ofrece el concepto de la sororidad en el campo del género.

\section{UN ESTUDIO DE CASO UBICADO EN LA SOCIEDAD CUBANA Y CUBANOAMERICANA}

Este estudio de caso explora la representación de la figura de la hermana en Las hermanas Agüero de Cristina García ${ }^{9}$. El artículo combina una perspectiva de género, al destacar una reescritura de mitos en los cuales las figuras femeninas juegan un papel protagonista, con una perspectiva transcultural, a través de la combinación de mitos procedentes de diferentes tradiciones tales como la española católica y la afrocubana.

\footnotetext{
${ }^{4}$ El mensaje a favor de la igualdad de género transmitido por el cuento conecta con el mismo argumento desarrollado en la ensayística de Angelina Muñiz Huberman: Houvenaghel, Eugenia Helena, «La mujer escritora en el ensayo de Angelina Muñiz Huberman», Escritoras españolas en el exilio mexicano, México, Porrúa, 2016, pp. 175-188.

${ }^{5}$ Zamudio, Luz Elena, «Angelina Muñiz Huberman», Material de Lectura, Cuento Contemporáneo, 117 (2011), p. 8.

${ }^{6}$ Watanabe, José, Antígona: Versión libre de la tragedia de Sófocles, Lima, Yuyachkani/Comisión de Derechos Humanos, 2000.

${ }^{7}$ Robles-Moreno, Leticia, «Yo soy la hermana que fue maniatada por el miedo: Performance política y políticas de memoria en Antíguna, de Yuyachkani», Hispanic Issues On Line, 17 (2016), pp. 127-128.

${ }^{8}$ Robles-Moreno, op.cit., p. 128.

${ }^{9}$ Novela publicada en 1997 en inglés bajo el título The Agüero Sisters (Knopf, 1997) y en español, en una traducción de Alan West, bajo el título Las Hermanas Agüero (Knopf, 1997). García, Cristina, Las Hermanas Agüero, New York, Knopf, 1997.
} 
En la novelística de Cristina García (La Havana, 1958) ${ }^{10}$, hija del exilio cubano en los Estados Unidos, las temáticas del país de origen y del exilio predominan. Acorde con esta constante, la crítica suele interpretar la narración The Agüero Sisters como una alegoría histórico-política. Acorde con esta interpretación, se consideran las hermanas que protagonizan la novela, Reina y Constancia Agüero, como representantes de la historia cubana o como dimensiones opuestas de la compleja identidad cubana ${ }^{11}$. Las hermanas encarnan una actitud contraria frente a la patria y la identidad nacional: Reina se ha quedado en Cuba y trabaja duro como electricista bajo Fidel Castro mientras que Constancia ha emigrado a Miami y, en el exilio, vende productos que recuerdan con nostalgia la Cuba tradicional. La reconciliación entre las dos hermanas al final de la novela representa, acorde con esta lectura político-histórica, la posibilidad de una reconciliación a nivel nacional. Reina, que representa a los cubanos fieles a Castro, y Constancia, que representa a los cubanos emigrados a los Estados Unidos con el fin de huir del régimen castrista.

La historia de la subdivisión de Cuba en dos partes, la Cuba del exilio y la del interior, se plasma en la novela a través de la metáfora de la relación entre la madre y sus dos hijas $^{12}$. En este contexto, la figura de la madre-Cuba atrae la atención de la crítica ${ }^{13}$ : una figura al mismo tiempo muda y central en la novela, ya que la trama gira en torno al misterio de la muerte de la madre, misterio que las dos hijas tienen que resolver necesariamente para encontrar la paz.

Este estudio complementa los análisis de la figura de la madre como metáfora de Cuba con un análisis de la relación entre las hermanas Agüero en clave de género. Dicha relación es dinámica. En una primera fase, la relación es muy hostil: las hermanas se odian entre ellas, son polos opuestos que tienen visiones contrarias de la muerte misteriosa de su madre. Al final de la novela, sin embargo, tiene lugar la reconciliación entre las dos hermanas y se resuelve el misterio central de la novela en torno a la muerte de su madre.

\section{Doble INTERTEXTo Mítico}

Sobre la base de las referencias frecuentes en la novela a elementos asociados al sol y a la luna, al día y a la noche, al amanecer y a la puesta del sol, el primer mito incluido en el intertexto ${ }^{14}$ es el mito griego sobre los hermanos Helios y Selene, dioses del Sol y de la Luna:

\footnotetext{
${ }^{10}$ Cristina García nació en La Habana en 1958 como hija de padre guatemalteco y de madre cubana. En 1961, su familia huyó de Cuba y se estableció en Nueva York. La autora publicó Dreaming in Cuban (1992), The Agüero Sisters (1997, novela ganadora del premio Janet Heidiger Kafka), A handbook to Luck (2007), The Lady Matador's Hotel (2010), King of Cuba (2013), Here in Berlin (2017).

${ }^{11}$ Ween, Lori. «Translational backformations: Authenticity and language in Cuban America», Comparative Literature Studies, 40, 2 (2003), pp. 127-141.

${ }^{12}$ Igual que en su primera saga, Dreaming in Cuban (1992), el protagonismo en esta segunda novela de Cristina García recae, efectivamente, en la familia.

${ }^{13}$ Véase Marmolejo McWatt, Amparo, «De poderes, agüeros y amuletos en Las hermanas Agüero», Hispanic Journal, 24, 1/2 (2003), pp. 187-201; Rodríguez, María Cristina, «Political Authority Figures as Distant Memories of a Forgotten Past», Journal of Carribean Literatures, 6, 2 (2009), pp. 55-63; Tate, Julee, «Matrilineal and Political Divisions in Cristina García's «Dreaming in Cuban» and "The Agüero Sisters"», Letras Femeninas, 32/2, 2006, pp. 145-163.

${ }^{14}$ Aunque en la hipertextualidad de Genette, la relación existente entre el hipertexto y el hipotexto se encuentra declarada de una manera más o menos explícita, me ocuparé, en este trabajo, de una novela que no explicita la relación con el hipotexto mítico. Argumento que la imagen de la hermandad transmitida
} 
[...] estos seres divinos, personificación de los astros, [...] rigen las vidas de todos desde lo más alto de la bóveda celeste: resplandecientes y bellos al máximo, montan en sus carros arrastrados por caballos y -elevándose desde el océano- recorren el cielo cíclicamente, constantemente, marcando así la sucesión del día y la noche ${ }^{15}$.

El mundo griego tiene una preferencia por la antítesis y los hermanos Helios y Selene son un ejemplo de dicha predilección por lo antitético. La oposición entre Helios, el astro del día o el sol masculino, y su hermana gemela Selene, el astro de la noche o la luna femenina, se manifiesta a través de diferentes aspectos del mito griego y en las mismas acciones de ambas figuras: «Selene con su postura suele indicar que se sumerge, a la inversa que su hermano Helios. Pues cuando éste se alza desde su lecho en el Océano, ella se hunde en las aguas ${ }^{16}$. Los movimientos de ambos son opuestos y evitan encontrarse. Helios se alza, Selene va en descenso. Selene solo comienza su viaje cuando Helios ya ha finalizado su viaje a través del cielo. Helios y su hermana son «incompatibles entre sí»» ${ }^{17}$.

De las antítesis tan características de la mitología griega «surge a menudo un tercer elemento, bien como síntesis, bien como intermedio transicional» ${ }^{18}$. Entre la Noche y el Día, interviene, acorde con este principio, un «intermedio transicional»: la tercera hermana, $\operatorname{Eos}^{19}$. Eos es la mediadora entre sus dos hermanos opuestos; en Eos (que es "tránsito") se funden los polos opuestos de Día y Noche, Sol y Luna. En el mito griego, Helios y Selene son tan contrarios que necesitan la intervención de una tercera hermana, la diosa del alba que anuncia la llegada de Helios. Eos es la diosa del amanecer que trae la luz del día al mundo y que precede el carro de su hermano Helios, quien "cada noche, descansa en el Océano y se baña para reaparecer, flotando en la copa de oro que le sirve de barca» ${ }^{20}$. La aparición de Eos, antes de su hermano Helios, se caracteriza como un instante mágico, un «tránsito» ${ }^{21}$ :

Eos es el tránsito entre los otros dos hermanos, que son incompatibles entre sí; se toca aún con ambos. Todavía se ve la luna en el cielo, hundiéndose en lo oscuro, mientras que en el otro extremo ya está clareando: es Eos, que comparte con Selene el firmamento, y se saludan... Hasta que surge el disco de

por los mitos antiguos, entre rivalidad y alianza, es vigente y esclarecedora para entender la historia sobre sororidad de García. La hipertextualidad es definida por Genette de la siguiente manera: «Entiendo por ella toda relación que une un texto B (que llamaré hipertexto) a un texto anterior A (al que llamaré hipotexto) en el que se injerta de una manera que no es la del comentario». Genette, Gérard, Palimpsestos: la literatura en segundo grado, Madrid, Taurus, 1989, p. 14.

${ }^{15}$ Esteban Santos, Alicia, «Los astros en la mitología y en la literatura griegas», en Esteban Santos, Alicia y Aguirre Castro, Mercedes (ed.), Cuentos de la mitología griega V. En el firmamento, Madrid, Ediciones de la Torre, 2008, p. 111.

${ }^{16}$ Esteban Santos, Alicia, «Eos: El dominio fugaz de la Aurora», Cuadernos de Filología Clásica: Estudios griegos e indoeuropeos, 12 (2002), p. 294.

${ }^{17}$ Esteban Santos, Alicia, «Los dioses astros», p. 12

${ }^{18}$ Ibid., p. 19.

${ }^{19}$ «Tea dio a luz al alto Helio, la brillante Selene y Eos, que alumbra a todos los seres de la tierra y a los inmortales dioses que habitan el vasto cielo, entregada al amor de Hiperión.» Hesíodo, Obras y fragmentos (introducción, traducción y notas), ed. de Aurelio Pérez Giménez y Alfonso Martínez Díez, Madrid, Gredos, 1978, pp. 371-372.

${ }^{20}$ Reyes, Alfonso, Obras Completas XVI: religión griega, mitología griega. México, Fondo de Cultura Económica, 1989, p. 119.

${ }^{21}$ Esteban Santos, Alicia, «Eos: El dominio fugaz de la Aurora», p. 294. 
fuego y se hace él solo con el dominio del cielo. Eos representa ese instante mágico, fugaz, entre la oscuridad y el día pleno de luz: es la intermediaria. Y es ella misma intermedia: rosada, azafranada, de suaves matices, entre el dorado relumbrante Helio y la pálida Selene ${ }^{22}$.

Sobre la base de la fuerte presencia de la divinidad morena de la patrona de Cuba, el segundo mito del cual se compone el intertexto que guía nuestra lectura es la historia de dicha santa, una virgen morena llamada la Virgen de la Caridad del Cobre o "la Cachita". La historia reza así: en 1687, tres pescadores, un esclavo negro y dos hermanos indios, se estaban ahogando en el mar durante una tempestad en la costa de El Cobre, un área de minas cerca de Santiago de Cuba. La Virgen mulata con el niño Jesús apareció a estos hombres y les salvó la vida. Por motivos de gratitud, los hombres construyeron un altar en su nombre en el sitio en el que ahora se encuentra el santuario de la Caridad del Cobre.

Dicha divinidad morena está formada por la sincretización de la orisha Oshún, de la religión africana yoruba, y la virgen católica ${ }^{23}$. Se trata, por lo tanto, de una figura sagrada doble que tiene su origen en la historia de Cuba. En la época del dominio español, los colonizadores católicos prohibieron la práctica de las tradiciones de los esclavos de origen africano, razón por la cual los esclavos asociaron cada orisha, o deidad del antiguo panteón yoruba, con un santo católico, con el fin de esconder su devoción a las tradiciones africanas. Así se creó la virgen morena de la Caridad del Cobre, como figura que fusiona la orisha Oshún y la Virgen católica.

A Oshún se une, en la religión yoruba, su hermana Yemayá, diosa blanca de la maternidad. Ambas divinidades se juntan en el agua y representan dos maneras de vivir el amor. Yemayá, asociada con la plata, es la diosa del amor, del mar y de la maternidad, que representa la mujer que cuida de los hijos, mientras que Oshún, asociada con el oro, es la diosa de la miel, de los ríos, del placer, del amor, de la sensualidad y de la sexualidad ${ }^{24}$.

La Virgen de la Caridad del Cobre, fusión de la diosa yoruba de la sensualidad con la Virgen católica, fue nombrada patrona de Cuba en 1916 y se venera en la Basílica construida en 1926 en el pueblo de El Cobre, cerca de Santiago de Cuba. Tras las primeras olas de exiliados cubanos a Miami, en los años 60, se consagró, a principios de los 70, una capilla a la Cachita en Miami, llamada la Ermita de la Caridad ${ }^{25}$. Los inmigrantes cubanos vienen a venerar a "la Cachita" en este santuario.

Este doble intertexto mítico -basado en el mito híbrido de la Caridad del Cobre, por un lado, y en el mito griego de Helios, Selene y Eos, por el otro- nos sirve de guía en la lectura de la historia de Las hermanas Agüero.

\footnotetext{
${ }^{22}$ Esteban Santos, Alicia, «Los dioses astros», pp. 12-13.

${ }^{23}$ Sobre las orishas, las fuerzas mágicas de la naturaleza basadas en la religión que el pueblo yoruba trajo desde Nigeria a Cuba, véase Bolívar Aróstegui, Natalia, Las orishas en Cuba, Havana, Ediciones Unión, 1990, quien ofrece una visión completa del "panteón afrocubano" y destaca con qué figuras del catolicismo las orishas se fusionan. El volumen de Bolívar Aróstegui, Natalia y Díaz de Villegas, José L., Espíritus rumberos, San Juan, Editorial Plaza Mayor, 2010, ofrece una selección de las leyendas de las orishas.

${ }^{24}$ Collier, Rhonda, «Mothering Cuba: The Poetics of Afro-Cuban Women», en Pereira Rocha, Elaine y Rosa Bezerra, Nielson (ed.), Another Black Like Me: The Construction of Identities and Solidarity in African Diaspora. Cambridge, Cambridge Scholar Publishing, 2015, pp. 67-68.

${ }^{25}$ Kunzel, George, «Cuba», A Taste of Latino cultures, 2005, p. 45.
} 


\section{LAS HERMANAS AgÜERO: RIVALIDAD}

La dualidad y la antítesis predominan la estructura de la primera parte de la novela y la caracterización de las hermanas, Constancia y Reina Agüero ${ }^{26}$. Los capítulos alternan y nos hablan, sucesivamente, de las vidas de Reina -en Cuba- y de su hermana Constancia -emigrada a Miami-. Reina es alta, fuerte, enérgica, dominante y trabaja como electricista. Su hermana Constancia, sin embargo, se presenta como el polo opuesto de su hermana: es pequeña, frágil, insegura y en la vida profesional concibe y vende sus propios productos de cosmética.

Reina es una mujer que ejerce una fuerza irresistible y magnética en los hombres por medio de su «cuerpo de muchas curvas»: «los hombres van detrás de ella, despacio, embobados por el tamaño y el meneo de sus nalgas $»^{27}$. Reina se caracteriza por gozar de su cuerpo y de su sexualidad ${ }^{28}$. Está muy orgullosa de su cuerpo, de su sensualidad y de su poder de seducción. El cuerpo de Constancia también está muy presente en la novela, pero de una manera muy diferente: Constancia «cuida su apariencia en extremo», ya que considera «que su propia imagen es la herramienta de venta más efectiva» a la hora de presentar sus productos de belleza ${ }^{29}$. Considera el estilo más importante que la comodidad. En cuanto a relaciones amorosas: Constancia se caracteriza por la fidelidad a su esposo, con quien vive una vida sin pasión amorosa al tiempo que considera imposible salir con otro hombre. El personaje de Constancia se construye sobre la base de descripciones de cremas de noche, loción de manos y perfumes destinados a mejorar su cuerpo y camuflar su inseguridad mientras que su hermana Reina se representa a través de las descripciones de sus conquistas amorosas.

La asociación de Constancia con la Luna se hace por medio de una insistencia en el color blanco y en el entorno de la noche. Selene, diosa de la Luna, es representada como una mujer hermosa de rostro pálido, conduciendo un carro de plata tirado por un yugo de bueyes blancos o un par de caballos. A menudo se le retrata montando un caballo o un toro, llevando una media luna sobre su cabeza y portando una antorcha. Constancia se asocia con la blancura: es muy pálida, tiene la piel muy blanca, usa siempre perlas blancas y se viste de blanco, vive en un apartamento «decorado con todo tipo de matices blan$\cos { }^{30}$. Se le asocia con la blancura de la nieve y Constancia se describe en muchas escenas nocturnas, caracterizadas por la oscuridad y la luna ${ }^{31}$. La primera vez que Reina ve a su hermana, quien fue echada de la casa materna desde muy pequeña, «se acuerda que pensaba que ya podía oír la luna, su largo e hiloso gemido de la soledad $»^{32}$.

La asociación de Reina con el Sol se hace por medio de la insistencia en el color rojo y en el entorno del día. Reina se describe en momentos en que la luz del día se anuncia o cuando hay una plena luminosidad. Se insiste en su piel oscura. Además, Reina se

\footnotetext{
${ }^{26}$ Por medio de la estructura del volumen, que alterna capítulos dedicados a cada una de las hermanas, se subraya el contraste entre Reina y Constancia. Aquí van las primeras frases de, respectivamente, los capítulos 1 y 2 de la novela y que se cruzan: «Reina Agüero, sujeta a un poste de teléfono, los muslos fortalecidos por muchas subidas, repara un cable de alto voltaje» (García, Cristina, Las hermanas Agüero, New York, Knopf, 1997, p. 7). El capítulo siguiente ofrece la primera imagen de su hermana: «Constancia Agüero ordena las filas de cajas verde-azuladas en su mostrador de cosméticos y fiscaliza su pintura de labios en el espejo magnificador» (Ibid., p. 17).

${ }^{27}$ Ibid, p. 8.

${ }^{28}$ Ibid., pp. 9, 13.

${ }^{29}$ Ibid., p. 19.

${ }^{30}$ Ibid., pp. 106, 67, 18, 18, 74, 181.

${ }^{31}$ Ibid., pp. 20, 25, 39, 41-42, 43 y 84.

32 Ibid., p. 67.
} 
relaciona con el color rojo, color del sagrado ganado rojo del sol de Helios, y el color de cobre en las minas de cobre en las que trabaja como electricista ${ }^{33}$. Otros elementos que caracterizan a Reina se relacionan con el fuego, recordando el carruaje de oro y fuego que Hefesto le había construido así como los corceles que arrojan fuego y que tiran el carro de Helios. El fuego también es un elemento predominante en la historia de su hijo Faetón que intentó conducir el carro de su padre Helios por el cielo pero perdió el control e incendió la Tierra. Reina se asocia también con el terremoto ${ }^{34}$, recordando cómo Faetón corre en el carro tan por encima de su curso habitual que la Tierra tiembla. Finalmente, Reina se vincula con el relámpago ${ }^{35}$, que recuerda el rayo con el que Helios mata a su hijo Faetón por haber quemado la tierra con su carro.

La divergencia entre el mito y la novela que llama la atención del lector es la inversión del sexo de Helios. La hermana que corresponde a Helios, Reina, no es varón sino mujer. Reina asume el papel de Helios: ejerce una profesión considerada tradicionalmente como masculina ${ }^{36}$ y tiene aficiones asociadas a la masculinidad. Sobre todo en cuestiones de amor y sexualidad se subraya su dominancia y su actitud activa, parecida a la del dios Helios, famoso por sus múltiples relaciones amorosas.

\section{Desarrollo del Conflicto entre las hermanas Agüero}

El encuentro imposible pero inevitable entre las hermanas Agüero antitéticas se anuncia de manera dramática: «Hay un telegrama pegado a la puerta [...]. El mensaje es de su hermana Reina, en La Habana. Dice que llega a Miami vía las Bahamas la próxima noche ${ }^{37}$. Reina abandona Cuba y llega a Miami, la ciudad en la que reside su hermana. El viaje de Reina a la ciudad de su hermana causa una ruptura en la estructura dual del libro, basada en la alternancia entre capítulos dedicados a Reina y a Constancia. Cuando las hermanas se encuentran, las tensiones son altas y las contradicciones evidentes. El carácter, al tiempo imposible e inevitable, del encuentro entre las dos hermanas recuerda el mito griego de los dioses del sol y de la luna.

Sobre todo las actitudes frente al cuerpo y frente a la sexualidad oponen diametralmente a las dos hermanas. Por un lado, la sensualidad de Reina, «su carne suave», causa conflictos: Constancia desaprueba la actitud de su hermana frente a la sexualidad. Reina se comporta de manera llamativa, reúne un gran número de admiradores, trabaja casi desnuda y confía en su cuerpo "hermoso, suave, generoso» y en sí misma ${ }^{38}$. El poder atractivo, magnético, de Reina no solo se relaciona con la sensualidad de su cuerpo, sino también con su capacidad técnica, su competencia profesional, su concentración, su atrevimiento. El cuerpo desnudo de Reina se describe repetidas veces en esta parte de la novela, admirado por hombres, sin pudor alguno y lleno de sensualidad. Los hombres la

\footnotetext{
${ }^{33}$ Ibid., pp. 12, 13, 32, 35, 37, 42.

${ }^{34}$ Ibid., p. 34.

${ }^{35}$ Ibid., pp. 7, 33.

${ }^{36}$ Esta tendencia a poner en entredicho los roles de género corresponde a una característica de los personajes femeninos construidos por Cristina García en su novelística. Pensemos, por ejemplo, en la matadora y en la ex-guerrillera, personajes femeninos que juegan un papel clave en The Lady Matador's Hotel: García, Cristina, The Lady Matador's Hotel, New York, Scribner, 2010.

${ }^{37}$ García, Cristina, Las hermanas Agüero, p. 143.

${ }^{38}$ Ibid., pp. 176, 167, 168, 177.
} 
consideran «una diosa» pero su hermana Constancia critica fuertemente la manera en la que Reina goza de su cuerpo ${ }^{39}$. Tras una noche de fiesta, por ejemplo, las tensiones entre ambas hermanas son intensas: «En el desayuno de esta mañana, Constancia la regañó por el número de hombres que había procesado en el club náutico. [...] ¡Y tú! ¡Tú ya tienes una Re-pu-ta-ción!». Se subraya el apetito para la pasión de Reina, que es «como el océano que estaba a sus pies, con su deseo de tragarse hombres vulnerables $»^{40}$.

Por otro lado, Reina siente compasión por Constancia, quien, sumisa a su marido, le es fiel en una relación sin pasión y tiene una vida sexual muy limitada en comparación con Reina. Reina le confiesa a su hermana que ha tenido relaciones sexuales con el marido de Constancia y compara la potencia limitada del mismo con el vigor sexual de «sus numerosas conquistas ${ }^{41}$. Constancia es insegura, sumisa y siente miedo a la aventura. Reina se ríe de muchas ansiedades y creencias de su hermana, tales como su confianza en los milagros: «Mucha bobería sobre nostalgia y femineidad que a Reina le ponía grave ${ }^{42}$. Reina opta explícitamente por actividades asociadas más bien con lo masculino: «Por lo menos a un automóvil, piensa, lo puedes arreglar, pintar, o mejorar su funcionamiento ${ }^{43}$. Reina, además, se hace muchas preguntas acerca de la imagen femenina que Constancia promueve por medio de sus productos de belleza. Reina pone en entredicho, así, el sentido de la profesión de su hermana. Cuestiona de manera crítica el objetivo de los productos que su hermana produce y ofrece, tales como cremas y perfumes: «¿Por qué una mujer quiere disfrazar su olor natural?», se pregunta Reina, «¿Por qué una mujer querría oler a algo que no fuera ella misma?» ${ }^{44}$.

Las burlas de Reina y los reproches de Constancia ponen en evidencia la incompatibilidad de las hermanas. El sol masculino Helios y la luna femenina Selene también son incompatibles. En el mito griego, sin embargo, el encuentro entre Helios y Selene se evita y no se pone en escena. La divergencia entre el mito y la novela consiste en que la novela sí pone en escena de manera explícita el encuentro entre las hermanas. La representación del conflicto entre el Sol y la Luna en la novela, gracias a la inversión del sexo del Sol, hace hincapié en la dualidad a la que la femineidad es reducida tradicionalmente. Al oponer dos modelos femeninos opuestos, el de Constancia - «una mujer/madre/esposa ejemplar según la lógica del patriarcado» ${ }^{45}$ - y el de Reina -la mujer seductora, la amante-, la novela pone en entredicho el sistema que encasilla a la mujer en uno u otro extremo de una dualidad impuesta.

\section{Eos: La Reconciliación mediada por la Virgen de la Caridad del Cobre}

¿Existe una figura intermediaria en la novela Las hermanas Agüero que corresponde a la tercera hermana Eos, personificación del alba? La figura a la que se apela para hacer

\footnotetext{
${ }^{39}$ Ibid., pp. 170, 208.

${ }^{40}$ Ibid., p. 177.

${ }^{41}$ Ibid., pp. 139, 166, 167.

${ }^{42}$ Ibid., p. 239.

${ }^{43}$ Ibid., p. 240.

${ }^{44}$ Ibid.

${ }^{45}$ Fernández Sánchez, José, «Paloma. Imágenes corporales: construcciones del cuerpo femenino en Las hermanas Agüero de Cristina García», Diálogos. Revista Electrónica, 16 (2005), p. 168.
} 
posible la reconciliación entre las hermanas Agüero es una figura sagrada doble y ambigua, la Virgen de la Caridad del Cobre o "la Cachita", patrona de Cuba.

Desde el punto de vista de la construcción de un modelo de feminidad, ambas figuras divinas se asocian con características femeninas muy diferentes. La Virgen es, en la tradición católica, la madre inmaculada del niño divino Jesús. La orisha Oshún, afrodita mulata, diosa de las aguas que vive en el río ${ }^{46}$, se caracteriza por seducir con su miel a los guerreros dejándoles así abandonar la guerra y mantener la paz ${ }^{47}$. Además, Oshún es la diosa del amor, de la coquetería, de la sensualidad y del erotismo ${ }^{48}$ : mantiene relaciones sexuales con muchos varones y en su totalidad tiene más de 200 maridos. El sincretismo religioso $^{49}$ fusiona ambas figuras divinas para formar "la Cachita". Se fusionan, así, dos arquetipos femeninos opuestos ${ }^{50}$ : una diosa que representa la madre virgen y otra diosa asociada con la sensualidad y la coquetería.

Desde el íncipit de la novela, la narración asocia cada una de las hermanas Agüero con la Virgen de la Caridad del Cobre al tiempo que alude al carácter sincrético de dicha figura divina. En las primeras páginas, Reina, electricista en la mina de El Cobre, se dirige a la Basílica para pedir ayuda a la Virgen de la Caridad del Cobre. En este momento la novela también refiere el nombre yoruba de la Virgen, Oshún. Constancia también se asocia, en el primer capítulo que protagoniza, con la doble dimensión de la Virgen de la Caridad del Cobre-Oshún: tiene afinidad con la Santería y los adivinos de Cuba al tiempo que se caracteriza por escuchar su programa favorito en la radio, La Hora de los Milagros, en la que se cuentan historias sobre milagros y visiones de la Virgen ${ }^{51}$.

La actitud de las dos hermanas frente a asuntos religiosos es opuesta. Reina, por un lado, no es una persona que tiene afinidad con la religión; se comporta de manera torpe en la iglesia, se dirige a la Virgen por medio de una oración poco respetuosa y «se irrita supremamente con la Virgen de la Caridad del Cobre» cuando ésta no le resuelve inmediatamente el problema ${ }^{52}$. La tendencia de Constancia a la religiosidad es más profunda, gracias a la niñera mulata que la educó en el marco de los ritos religiosos que tienen sus raíces en el África occidental, especialmente en la santería yoruba. Así es que la niñera mulata «le indujo a la pequeña Constancia a los misterios más valiosos en la vida ${ }^{53}$. A pesar de las diferencias entre la actitud de ambas mujeres frente a la religión, el lector percibe que la figura sincrética de "la Cachita" vincula a las hermanas y funciona como intermediadora.

Las hermanas, en su búsqueda de una solución al conflicto en torno a la muerte de su madre, se dirigen a "la Cachita" para pedirle ayuda. La preparación de la reconciliación

\footnotetext{
${ }^{46}$ Oshún es también el nombre de un río que fluye en el río Níger en África.

${ }^{47}$ Castellanos Llanos, Gabriela, «Identidades raciales y de género en la santería afrocubana», La manzana de la discordia, 4, 1 (2009), pp. 63-72.

${ }^{48}$ Véase Canizares, Baba Raúl, Oshun: Santería and the Orisha of Love, Rivers and Sensuality, Original Publications, 2000.

${ }^{49}$ Véase Donadoni, Chiara y Houvenaghel, Eugenia Helena, «La hibridez de la tradición judeocristiana como reivindicación del sincretismo religioso en la Nueva España», Neophilologus, 94, 3 (2010), pp. 459475.

${ }^{50}$ Desde un punto de vista histórico-cultural, la figura doble y transitoria representa la hibridez cultural del pueblo cubano, en el que el elemento africano y el europeo se fusionan. Volveremos sobre dicha hibridez cultural más adelante.

${ }^{51}$ García, Cristina, Las hermanas Agüero, op.cit., p. 127.

${ }^{52}$ Ibid., pp. 10-11.

${ }^{53}$ Ibid., p. 24.
} 
entre las hermanas se sitúa en un ambiente lleno de magia para realizar un rito de purificación: las hermanas van a un santero el día de Oshún, que es también el día de la Virgen de la Caridad del Cobre. Encienden velas para iniciar el hechizo, se encuentran en un lugar sagrado cerca del río, un santero les ayuda, palabras sagradas son pronunciadas, el agua del río es vertida sobre sus cabezas, las hermanas van vestidas de blanco y «Constancia se ve más alta bajo la luna, como una sacerdotisa sagrada» ${ }^{54}$.

Tras este inicio del rito, las hermanas entran en el barco y se van por el río. Sin embargo, «bajo la media luna», las dos hermanas entran en conflicto y Reina cae en el río. Constancia, observa a «su hermana ahogarse, y, además, tiene que contenerse para no meter la cabeza de Reina bajo agua de nuevo», para no «rajarle el cráneo a su hermana con el remo y llegar al meollo» ${ }^{55}$. El amanecer, sin embargo, trae la solución. La referencia al amanecer se introduce en un lugar clave de la novela: la novela se termina cuando llega, significativamente, el alba: «el horizonte enrojece de amanecer ${ }^{56}$. Es en este momento que Constancia le salva la vida a su hermana Reina, que está ahogándose en el mar. Constancia «engancha a Reina» con el remo roto "por el cuello de su chaqueta empapada y con una fuerza inesperada», la coloca a bordo del barco. Constancia le da boca a boca «hasta que el pecho de Reina sube y baja de su propio esfuerzo» ${ }^{57}$.

En este ambiente, en el que se combinan el agua y el amanecer, tiene lugar la reconciliación. A través de la figura de la Virgen de la Caridad del Cobre, se resuelve la antítesis y se propone una manera plural de concebir la femineidad, más allá de una visión binaria.

\section{LA RESIGNIFICACIÓN DE LA FIGURA DE LA HERMANA MítICA}

A través de una narración que concede un lugar central a la tensión entre dos hermanas opuestas, la novela de Cristina García llama la atención, no tanto sobre un objeto deseado disputado por ambas hermanas -tal como una fortuna, el poder, una tierra, el amor-, sino más bien sobre la polaridad misma que caracteriza la imagen de la femineidad impuesta por la sociedad y que determina la manera en la que la mujer se concibe a sí misma.

Un elemento clave en la novela de García es la puesta en escena del conflicto entre los polos opuestos. El mito griego del Sol y de la Luna carece de esta dimensión: separa los hermanos opuestos e introduce una figura intermediaria, la tercera hermana Eos, precisamente para evitar el encuentro entre el Sol y la Luna. Así, el mito parece eternizar la antítesis y repetir para siempre su ciclo de oposición. La novela de García, en cambio, sí procura hallar una solución para el conflicto a través de la confrontación. La narración contiene escenas altamente conflictivas e incluso una escena de violencia entre ambas hermanas. De este modo, la novela conecta con la tradición del fratricidio que atraviesa

\footnotetext{
${ }^{54}$ Ibid., pp. 279-280.
}

${ }^{55}$ Además, la historia de Reina, quien casi se ahoga, recuerda que en la mitología griega, Helios se muere ahogado por los Titanes, los hermanos celosos de Basilea (la madre de Helios). En la novela se cita además otra versión de este aspecto del mito, recitado por un santero, en la que se alude al ahogamiento de la descendencia del sol: «Hace mucho tiempo, el sol se casó con la luna y tuvieron muchos niños. Sus hijas eran estrellas y se quedaron cerca de su madre. Pero los hijos siguieron a su padre por el cielo de la mañana. Pronto, el padre se puso bravo y ordenó que sus hijos volvieran a casa. Los varones, pequeños soles ellos mismos, cayeron en el mar y se ahogaron. Por eso el sol arde solo mientras la luna comparte el cielo». Ibid., p. 267.

\footnotetext{
${ }^{56}$ Ibid., p. 286.

${ }^{57}$ Ibid., p. 287.
} 
la visión mitológica de la hermandad como un hilo rojo. Caín mató a su hermano y rival Abel por envidia, Medea mató a su hermano Apsirto para ayudar a su amante Jasón a escapar con el vellocino de Oro, Rómulo mató a Remo por traspasar los límites de la ciudad de Roma, Polinices y su hermano enemigo Eteocles se mataron mutuamente por el trono de Tebas.

Sin embargo, la novela se aleja de la tradición del fratricidio porque Constancia no deja morir a su hermana, quien está a punto de ahogarse, sino que termina por salvarle la vida. $\mathrm{Su}$ actitud recuerda a la de la hermana Isis, quien simboliza la lealtad al hermano Osiris, asesinado por la figura del hermano traicionero Set. El acto interrumpido de fratricidio/ rivalidad se convierte en una alianza que cuestiona los modelos predominantes de la mujer en la sociedad.

$\mathrm{Al}$ introducir la figura polifacética y ambivalente de la Virgen de la Caridad como un tercer modelo de femineidad a través del cual ambas hermanas se aceptan mutuamente, la novela parece abogar por un concepto de femineidad más abarcador y diverso. En efecto, la Virgen de la Caridad del Cobre, símbolo del sincretismo cubano, es el fruto de la fusión de dos raíces esenciales, una procedente de España y otra de África, y cada una representa una imagen distinta de la femineidad. Al incluir y fusionar elementos culturales de etnias culturales tan diferentes y tan difícilmente compatibles, la Virgen de la Caridad consigue encarnar la esencia de Cuba. De una manera paralela, al incluir y fusionar concepciones de la femineidad opuestas y aparentemente incompatibles, la Virgen de la Caridad logra captar la esencia ambivalente de lo femenino.

La lectura en diálogo con el intertexto mítico revela cómo Las hermanas Agüero pone en entredicho la oposición entre dos modelos de femineidad y culmina en la transgresión de dicha visión binaria a través de la figura ambivalente de Eos, la tercera hermana de Helios y Selene, que simboliza el Alba. La novela promueve un nuevo modelo plural de femineidad, más allá de binarismos, una imagen de la mujer que es ambivalente y cuyo carácter ambiguo le permite superar la polaridad y la hostilidad. Las hermanas Agüero crea un imaginario alternativo de la sororidad en el que la fusión de polos opuestos, la transgresión de fronteras y la atención por el difícil camino hacia la alianza predominan. La renovada imaginación de la figura de la hermana mítica en la novela de García pone en escena el proceso dificultoso de la remodelación de la mujer y contribuye, así, a la resignificación de la feminidad en la sociedad cubana y cubanoamericana.

\section{REFERENCIAS BIBLIOGRÁFICAS}

Bolívar Aróstegui, Natalia, Las orishas en Cuba, Havana, Ediciones Unión, 1990.

Bolívar Aróstegui, Natalia y Díaz de Villegas, José L., Espíritus rumberos, San Juan, Editorial Plaza Mayor, 2010.

Canizares, Baba Raúl, Oshun: Santería and the Orisha of Love, Rivers and Sensuality, Original Publications, 2000.

Collier, Rhonda, «Mothering Cuba: The Poetics of Afro-Cuban Women», en Pereira Rocha, Elaine y Rosa Bezerra, Nielson (ed.), Another Black Like Me: The Construction of Identities and Solidarity in African Diaspora, Cambridge, Cambridge Scholar Publishing, 2015, pp. 65-96. 
Donadoni, Chiara y Houvenaghel, Eugenia Helena, «La hibridez de la tradición judeocristiana como reivindicación del sincretismo religioso en la Nueva España», Neophilologus, 94, 3 (2010), pp. 459475.

Esteban Santos, Alicia, «Eos: El dominio fugaz de la Aurora», Cuadernos de Filología Clásica: Estudios griegos e indoeuropeos, 12 (2002), pp. 287-318.

-, «Los dioses astros», en Esteban Santos, Alicia y Aguirre, Mercedes (ed.), Cuentos de la mitología griega V. En el firmamento, Madrid, Ediciones de la Torre, 2008, pp. 11-54.

-, «Los astros en la mitología y en la literatura griegas», en Esteban Santos, Alicia y Aguirre, Mercedes (ed.), Cuentos de la mitología griega V. En el firmamento, Madrid, Ediciones de la Torre, 2008, pp. 109-126.

Fernández Sánchez, José, «Paloma. Imágenes corporales: construcciones del cuerpo femenino en Las hermanas Agüero de Cristina García», Diálogos. Revista Electrónica, 16 (2015), pp. 163-181.

García, Cristina, Las hermanas Agüero, trad. de Alan West, New York, Knopf, 1997. (ed. orig.: The Agüero Sisters, New York, Knopf, 1997)

-, The Lady Matador's Hotel, New York, Scribner, 2010.

Genette, Gérard, Palimpsestos: la literatura en segundo grado, Madrid, Taurus, 1989.

Girard, René, La violencia y lo sagrado, Barcelona, Anagrama, 2005.

Graves, Robert y Patai, Raphael, Los mitos hebreos, Madrid, Alianza, 2000.

Hesíodo, Obras y fragmentos, (introducción, traducción y notas), ed. de Aurelio Pérez Jiménez y Alfonso Martínez Díez, Madrid, Gredos, 1978.

Houvenaghel, Eugenia Helena, «La mujer escritora en el ensayo de Angelina Muñiz Huberman», en Houvenaghel, Eugenia Helena (ed.), Escritoras españolas en el exilio mexicano, Porrúa, 2016, pp. 175-188.

Kunzel, George, «Cuba», A Taste of Latino cultures, 2005, pp. 41-52.

Llano Cifuentes, Alejandro, Deseo, violencia, sacrificio. El secreto del mito según René Girard, Pamplona, Eunsa, 2004.

Muñiz-Huberman, Angelina, Huerto cerrado, huerto sellado, México, Oasis, 1985.

Robles-Moreno, Leticia, «Yo soy la hermana que fue maniatada por el miedo: Performance política y políticas de la memoria en Antígona, de Yuyachkani», HIOL Hispanic Issues On Line, 17 (2016), pp. 126-143.

Rodríguez, María Cristina, «Political Authority Figures as Distant Memories of a Forgotten Past», Journal of Carribean Literatures, 6, 2 (2009), pp. 55-63.

Tate, Julee, «Matrilineal and Political Divisions in Cristina García’s Dreaming in Cuban and The Agüero Sisters», Letras Femeninas, 32, 2 (2006), pp. 145-163.

Watanabe, José, Antígona: Versión libre de la tragedia de Sófocles. Lima, Yuyachkani/Comisón de Derechos Humanos, 2000.

Ween, Lori, «Translational backformations: Authenticity and language in Cuban America», Comparative Literature Studies, 40, 2 (2003), pp. 127-141.

Zamudio, Luz Elena. «Angelina Muñiz Huberman», Material de Lectura. Cuento contemporáneo, 117 (2011), pp. 8-10. 